\title{
MODELLING MODAL SHIFT DUE TO THE ENHANCED LEVEL OF BUS SERVICE
}

\author{
Perumal Vedagiri $^{1}$, Venkatachalam Thamizh Arasan ${ }^{2}$ \\ Transportation Engineering Division, Dept of Civil Engineering, Indian Institute of Technology Madras, \\ Chennai - 600 036, India \\ E-mails: ${ }^{1}$ transpoveda@gmail.com; ${ }^{2}$ arasan@iitm.ac.in
}

Received 10 October 2008; accepted 10 April 2009

\begin{abstract}
This study is concerned with the estimation of the probable shift of auto-rickshaw (three wheeled motorized para-transit vehicle) users to the bus due to an increase in its level of service after providing exclusive bus lanes on Indian city roads carrying heterogeneous traffic. The quantum of an increase in the level of bus service due to the introduction of an exclusive bus lane was determined using a recently developed simulation model of heterogeneous traffic flow. The data on other factors (variables) that might cause modal shift from the auto-rickshaw to the bus was collected conducting a home-interview survey based on the stated preference approach. A binary logit model of modechoice was then calibrated using the collected data and the model was also validated using a holdout sample. A modechoice probability curve to depict the possible shift of auto-rickshaw users to the bus is developed taking difference in the travel times of two-modes as the basis to serve as a user friendly tool to analyze the possible modal shift for a wide range of the values of the involved variables.
\end{abstract}

Keywords: heterogeneous traffic flow, exclusive bus lane, auto-rickshaw, modal shift, stated preference approach, binary logit model, mode-choice probability curve.

\section{Introduction}

Transport demand has substantially increased in most Indian cities due to an increase in urban population as a result of both internal growth and migration from rural areas and small towns. The high rate of the growth of Indian economy has also significantly contributed to an increase in demand. The bus is the main urban transit system used in most Indian cities and gradually, its level of service is declining due to inadequate capacity and managerial and financial problems. In the absence of an adequate and efficient bus transit system, potential bus users currently use private transport modes - mainly motorized two-wheelers and, to some extent, cars. Also, some of them resort to the use of a para-transit mode called auto-rickshaws (three-wheeled motorized vehicles to carry passengers based on fare rate) that are very popular and common transport means in many Asian cities. Thus, a large number of private and para-transit vehicles have entered the market to meet travel demand. As the available road space is limited, the proliferation of these vehicles results in severe congestion, inordinate delay, high-energy consumption (particularly of fossil fuels) and intense pollution of the environment.
Traffic on the roads of Indian cities is highly heterogeneous comprising the vehicles of wide ranging static and dynamic characteristics. The vehicles occupy any lateral position on the road depending on the availability of road space at a given instant of time without any lane discipline, and thus it is nearly impossible to impose lane discipline under such conditions. Under the introduced heterogeneous traffic flow conditions, buses being relatively larger vehicles, find difficulties in maneuvering through mixed traffic and are subjected to frequent acceleration and deceleration leading to lower speed and discomfort to both the driver and passengers. This also results in enormous delay and uncertainty to bus passengers and consequently, the level of bus service gets reduced considerably making the bus a less attractive mode of transport. Indian cities desperately need improved and expanded public transport service rather than personal vehicles. This requires both an increase in quantity as well as in the quality of bus transport service and an effective application of demand including supply-side management measures. This goal can be attained by encouraging bus transport assigning priority to it. One of the common bus preferential treatments is the provision of reserved bus lanes on major urban roads to facilitate a faster movement of buses 
which will make the mode more attractive. The provision of exclusive road space, thus, will enhance the level of bus service and may also result in shifting some personal para-transit vehicle users to buses. This study is intended to estimate the probable shift of the para transit vehicle (auto-rickshaw) users to buses using an appropriate mode-choice modelling technique to assess impact, in respect of modal shift, of providing exclusive bus lanes.

\section{Review of the Previous Studies}

A modal shift occurs when one mode gains a comparative advantage in a travel market over another. The comparative advantage can take various forms such as costs, capacity, time, flexibility or reliability. Depending on a kind of passengers traveling and their circumstances (socio-economic characteristics, purpose of trip etc.), the relative importance of each of these factors vary (Khaki et al. 2009). Mode choice models effectively could be divided into two classes:

1. models that cover all available modes;

2. models focusing on selected modes only (Gebeyehu and Takano 2005).

The former type of the model is necessary where demand forecast is required for all modes as would be the case if a broader social cost-benefit appraisal of a transport scheme is conducted. If one is solely interested only in two modes, a binary choice model (e. g Rao 1993; Arasan et al.1996; Ghareib 1996; Hamed and Easa 1998) is more appropriate. For example, to study how many travelers may be attracted from the auto-rickshaw to the bus, only the auto-rickshaw and the bus need to be taken into consideration.

As this study pertains to the analysis of modal shift from the auto-rickshaw to the bus, the review of the presented literature is confined to research works related to choosing the behaviour of travelers under conditions wherein one of the involved modes is the bus and the analyses are related to modal shift. Tischer and Dobson (1979) studied factors influencing the intentions of single-occupant commuters to switch to buses and carpools and suggested operating policies consistent with the intent to encourage the use of high-occupancy vehicles. They found that in buses, convenience was the most important variable associated with shift intention. They also found that the perceptions of carpool comfort do not appear to be important, rather, the perceptions of carpool schedule flexibility, cost, safety and a short wait in traffic were found to be the prime factors associated with potential shift to carpool. Alvinsyah et al. (2005) developed a binomial logit model based on Stated Preference (SP) data to study the response of the travelers in using the proposed Jakarta bus-way system. Travel time and travel cost were considered as the main variables to develop utility functions. Based on these modal characteristics and different service strategies offered, peoples' perception and their probability of selecting the proposed system are predicted. The results show a wide range of peoples' perception and their probability of choosing a better service.
Nurdden et al. (2007) identified the factors that prevent personal transport users from utilizing public transport, so that rational polices could be formulated to encourage greater utilization of public transport. Binary logit models were developed involving a car and a bus as well as a car and a train. The most important variables, found likely to encourage the use of public transport, were reduced travel time, walking distance to public transport stations and subsidized fare. Gebeyehu and Takano (2007) studied the citizens' perceptions of bus condition as a determining factor for their choice of bus transportation and developed a binary logit model to analyze the behaviour of traveler's choice. The result of the study shows that the citizens' perceptions of the three chosen bus-transit condition aspects (fare, convenience and frequency) have a significant influence on choosing a public-transport-mode. Mackett (2003) identified different policy actions to reduce car use for different types of trips and actions that are required to meet travelling needs the car currently fulfils. Then, evidence on why people used their cars for a set of real short trips is considered in terms of a number of dimensions including age, sex and trip purpose. This is followed by a discussion of alternative modes to the car that drivers say they might adopt and the factors they accept would make them consider switching to these alternatives. The analysis of the surveyed results shows that improving public transport' is a specific action, and therefore drivers find it as the most likely one to attract them out of their cars.

Basu and Maitra (2007) applied their models to use valuing attributes of enhanced traffic information to investigate transport traffic in Kolkata. Ušpalytė-Vitkūnienè et al. (2006) investigated methods and models for public transport network calibration in Vilnius. Tanczos and Torok (2007) studied the linear optimization model of operating transportation efficiency in urban areas. Ziari et al. (2007) investigated models for locating stations of public transportation vehicles to improve transit accessibility.

All these studies, in summary, are motivating and shed some light on the factors that influence the way individuals decide to choose their modes of travel and the contrasting roles of perceptions and satisfactions in their ability to respond to switching intentions to buses. At present, there is no research material available in the behavioral study of the switching intention of personal vehicle users to buses under traffic conditions prevailing in developing countries, and this study is an attempt to fulfill this need.

\section{Methodology}

As per the available literature, two different approaches are used in mode choice analysis:

- Revealed Preference (RP) Approach;

- Stated Preference (SP) Approach.

The RP approach has been used to model modechoice when data on an actual choice of mode by travellers is available. Whereas, the SP approach has been used to analyze the response of people to hypothetical choice situations which, certainly, can cover a wider 
range of attributes and conditions than the real system. In the present study, the SP approach has been adopted for model development. Since the modes considered were only the bus and the auto-rickshaw, a binary choice model has been used. As interpretation and specification is straight forward in the logit model rather than in the probit model, the logit model was adopted for the study.

\section{Model Specification}

In our case, model specification is based on the utility theory supported by an assumption that individuals select the mode that maximizes their utility $(U)$. The Utility theory enables predicting changes in choices that occur when an attribute of one of the alternatives changes. Moreover, the utility based model is able to capture differences in the responses of different individuals to the same attribute change. The utility of an alternative ' $i$ ' is assumed to be made up of two terms:

- a deterministic term $(V)$ representing systematic and observed effects;

- a random term $(\varepsilon)$ representing unobserved factors affecting the choice.

The random-error term $\varepsilon$ is assumed to be independently and identically distributed as per the Gumbel distribution. As per this specification, an individual is likely to shift from the auto-rickshaw to the bus if the utility of bus mode is more than the utility of the autorickshaw. Without the loss of generality, the utility of shift is given as the difference between the utilities of the bus and the auto-rickshaw. Therefore, a traveler is likely to shift from the auto-rickshaw to the bus if utility difference, $U_{\text {diff. }} \geq 0$. The utility of shifting is also assumed to be made up of two terms: a deterministic term $\left(V_{\text {diff. }}=V_{B u s}-\right.$ $\left.V_{\text {Auto-rickshaw }}\right)$ representing systematic and observed effects and a random term $\left(\varepsilon_{\text {diff: }}=\varepsilon_{\text {Bus }}-\varepsilon_{\text {Auto-rickshaw }}\right)$ representing unobserved factors affecting choice. Based on the above introduced assumptions, it can be shown that $\varepsilon_{\text {diff. }}$ is distributed as per logistic distribution. Therefore, the probability of shift,

$$
\begin{aligned}
& P_{\text {shift }}=\operatorname{Pr}\left(U_{\text {diff. }} \geq 0\right)=\operatorname{Pr}\left(V_{\text {diff. }}+\varepsilon_{\text {diff. }} \geq 0\right)= \\
& \frac{e^{V_{\text {diff. }}}}{1+e^{V_{\text {diff }}}} \geq 0 .
\end{aligned}
$$

Deterministic term $V_{\text {diff }}$ is assumed to be given by a linear-in-parameters specification. Accordingly,

$$
V_{\text {diff. }}=A_{0}+A_{1} X_{1}+\ldots \ldots+A_{\mathrm{n}} X_{\mathrm{n}} .
$$

Therefore, the probability of shift can be given as,

$$
P_{\text {shift }}=\frac{e^{V_{\text {diff. }}}}{1+e^{V_{\text {diff. }}}}=\frac{e^{A_{0}+A_{1} X_{1}+A_{2} X_{2}+\ldots \ldots+A_{n} X_{n}}}{1+e^{A_{0}+A_{1} X_{1}+A_{2} X_{2}+\ldots \ldots+A_{n} X_{n}}},
$$

where: $P_{\text {shift }}$ is the probability of shift from the auto-rickshaw to bus mode; $V_{\text {diff. }}$ is the deterministic utility function of difference in the utilities of the bus and the auto-rickshaw $A_{0}, A_{1}, A_{2} \ldots$ are the model parameters to be estimated $X_{1}, X_{2} \ldots$ are variables influencing modal shift.

\section{Data Base for the Stated Preference Survey}

As an objective in this case is to predict the aggregate shift of auto-rickshaw users to the bus consequent on reduction in the travel time of buses due to the provision of exclusive bus lanes. Thus, it is necessary to estimate the possible reduction in the travel time of buses due to the provision of exclusive bus lanes under the prevailing roadway and traffic conditions. For this purpose, the Chennai city situated in the south eastern part of India was considered as an example. The major roads in Chennai city carry a significant amount of bus traffic and are either six-lane or eight-lane divided roads. Thus, the width of road space available for one-way movement on these roads is equivalent to either three or four lanes which are sufficient to allocate one lane exclusively for buses. To conduct the stated preference survey, it is necessary to know the speeds of buses and auto-rickshaws on these two types of roads for a wide range of trafficvolume conditions and this can be achieved through appropriate traffic simulation experiments. As the available simulation models are based on fairly homogeneous traffic conditions, where, strict lane discipline exists, these models are not suitable for simulating Indian traffic conditions. Hence, a recently developed and validated model of highly heterogeneous traffic flow prevailing on Indian roads (Arasan and Koshy 2005) was used for this study for the purpose of which a traffic composition representing the mean composition of traffic on the major roads of Chennai city was considered (Fig. 1). The roadway width for the simulation of traffic flow in one direction was fixed as $11.0 \mathrm{~m}$ ( 3 lanes) and $14.5 \mathrm{~m}$ (4 lanes). The traffic flow on the assumed arterials was simulated for road conditions with and without bus lane for a wide range of traffic volume (from near free flow condition to capacity level).

The journey speed of buses and auto-rickshaws obtained through the simulation experiment for the roadway and traffic conditions considered is depicted in Fig. 2. As per recommendations of Indian Roads Congress (IRC), the desirable level of service for urban roads is ' $\mathrm{C}$ ' and the corresponding traffic volume level is equal to about 0.7 times to capacity (Indian ... 1990). Hence, it would be appropriate to consider this

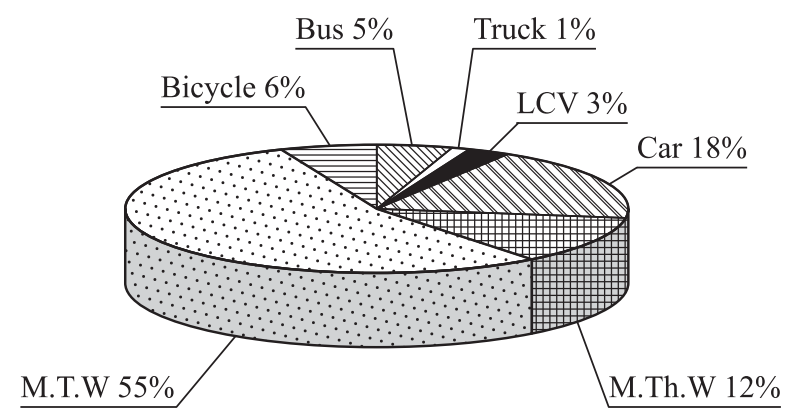

LCV - Light Commercial Vehicles,

M.Th.W. - Motorised Three-Wheelers (Auto-Rickshaws), M.T.W. - Motorised Two-Wheelers

Fig. 1. Representative traffic composition 


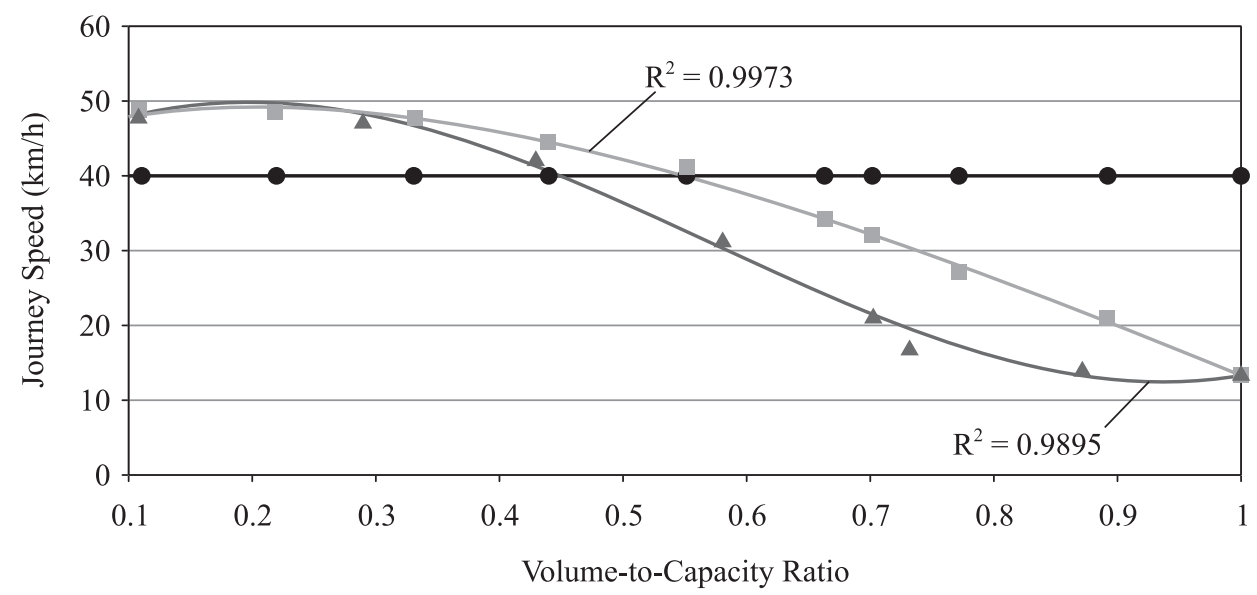

Journey Speed of Bus

Journey Speed of Auto-Rickshaw (4-Lane)

- Journey Speed of Auto-Rickshaw (3-Lane)

Fig. 2. Journey speed of buses and auto-rickshaws

value (volume-to-capacity ratio $=0.7$ ) as the base for determining speed difference between the bus and the auto-rickshaw. Accordingly, it can be seen that difference in journey speed (alternatively difference in invehicle travel time) between buses (on exclusive lane) and auto-rickshaws expressed as the percentage of bus speed falls in the range of about 19 to $47 \%$ when both roadway conditions (three lane and four lane) are considered together. This result was used as the base to prepare the questionnaire for the SP survey.

\section{Study Area and Survey Design}

In order to apply a model in practice, it is necessary to estimate the model parameters using the surveyed data. To study the effect of reduction in travel time on the demand for bus travel, a Stated Preference (SP) questionnaire was prepared. Data on the factors (variables) that might cause modal shift from the auto-rickshaw to the bus was collected through a home-interview survey conducted in the residential area, named Todhunter Nagar in the southern part of Chennai city, India, which has reasonable accessibility to bus service (walking time to bus stop varies from 3 to 15 minutes). The home-interview survey was carried out in households using autorickshaws. During the survey, the respondents were asked to base their response on their previous day trips. The questionnaire had provision to collect data on the following attributes:
a) gender;
b) age;
c) walking time to bus stop;
d) trip purpose;
e) willingness or otherwise to shift to bus for various in-vehicle travel time differences (bus travel time being $0,10,20,30$ and $40 \%$ less than travel time by the auto-rickshaw).

The list of variables considered for modelling and their relevant descriptions are given in Table 1.

\section{Model Development}

\subsection{Model Calibration}

Model calibration or estimation involves finding the values of parameters that make the observed data more likely under the model specification; in this case, one or more parameters can be judged non-significant and left out of the model. The estimation also considers the possibility of examining empirically certain specification issues, for example, the structural and/or functional form of parameters may be estimated. In this study, the stated preference (willingness or otherwise to shift) of the respondent is dependent variable and gender, age, walking time to bus stop, trip purpose and in-vehicle travel-time difference are the independent variables considered for model estimation. As the dependent variable is discrete in nature, the model was calibrated by maximum-likelihood estimation using Newton Raphson method. For a fixed set of data and underlying probability model, the maximum-likelihood picks the values of model parameters that make the data 'more likely' than any other values of the parameters would make them.

The home-interview survey was conducted with 100 auto-rickshaw users. The data set pertaining to 100 auto-rickshaw users with their responses for shifting to the bus (for five travel-time-difference scenarios) was processed into $500(5 \times 100)$ data points for modelling. For the purpose of model calibration, a set of 400 data points ( $80 \%$ of the total) was used while setting aside the rest of observations (20\%) for the purpose of validation. For model-calibration analysis, a software tool, named, Statistical Software Tools (SST) was used. The goodnessof-fit for the calibrated model can be assessed by the likelihood ratio index $\left(\rho^{2}\right)$, which is given as,

$$
\rho^{2}=\frac{L L(P)-L L(0)}{L L(0)}
$$

where: $L L(P)-\log$-likelihood of the estimated model; 
Table 1. Description of the variables considered for modeling

\begin{tabular}{|c|c|}
\hline Variable name & Description and coding details \\
\hline Gender & Male/Female. The variable will be assigned the value 0 if male and 1 if female. \\
\hline Age 1 & $\begin{array}{l}\text { People aged from } 10 \text { to } 20 \text { years old. The variable will be assigned the value } 1 \text { if a respondent falls in the } \\
\text { right age group and } 0 \text { if it is not. }\end{array}$ \\
\hline Age 2 & $\begin{array}{l}\text { People aged from } 21 \text { to } 40 \text { years old. The variable will be assigned the value } 1 \text { if a respondent falls in the } \\
\text { right age group and } 0 \text { if it is not. }\end{array}$ \\
\hline Age 3 & $\begin{array}{l}\text { People aged from } 41 \text { to } 60 \text { years old. The variable will be assigned the value } 1 \text { if a respondent falls in the } \\
\text { right age group and } 0 \text { if it is not. }\end{array}$ \\
\hline Age 4 & $\begin{array}{l}\text { People who are over } 60 \text { years old. The variable will be assigned the value } 1 \text { if a respondent falls in the } \\
\text { right age group and } 0 \text { if it is not. }\end{array}$ \\
\hline Walking Time 1 & $\begin{array}{l}\text { Walking time to the bus stop is } \leq 5 \text { minutes. The variable will be assigned the value } 1 \text { if the walking time } \\
\text { of a respondent falls in the required range of time and } 0 \text { if it is not. }\end{array}$ \\
\hline Walking Time 2 & $\begin{array}{l}\text { Walking time to the bus stop is } 6-10 \text { minutes. The variable will be assigned the value } 1 \text { if the walking } \\
\text { time of a respondent falls in the required range of time and } 0 \text { if it is not. }\end{array}$ \\
\hline Walking Time 3 & $\begin{array}{l}\text { Walking time to the bus stop is more than } 10 \text { minutes. The variable will be assigned the value } 1 \text {, if the } \\
\text { walking time of a respondent falls in the required range of time and } 0 \text { if it is not. }\end{array}$ \\
\hline Trip-W & $\begin{array}{l}\text { Trip for work purposes. The variable will be assigned the value } 1 \text { if the trip under consideration is made } \\
\text { for work and } 0 \text {, otherwise. }\end{array}$ \\
\hline Trip-E & $\begin{array}{l}\text { Trip for education purposes. The variable will be assigned the value } 1 \text { if the trip under consideration is } \\
\text { made for education and } 0 \text {, otherwise. }\end{array}$ \\
\hline Trip-O & $\begin{array}{l}\text { Trip for other purposes. The variable will be assigned the value } 1 \text { if the trip under consideration is made } \\
\text { for other purpose and } 0 \text {, otherwise. }\end{array}$ \\
\hline $\begin{array}{l}\text { Stated Preference } \\
\text { (dependent variable) }\end{array}$ & rip maker prefers to shift to the bus and 0 , otherwise. \\
\hline
\end{tabular}

$L L(0)$ - log-likelihood when the coefficients are assumed to be zero.

Model-calibration results are shown in Table 2. It can be seen that the signs of the parameters of the variables are logical. The value of the t-statistic for different variables when compared with the corresponding table value indicates that all parameter estimates are significant at $2.5 \%$ level.

Table 2. The results of model calibration

\begin{tabular}{lcc}
\hline Variable & $\begin{array}{c}\text { Parameter } \\
\text { estimate }\end{array}$ & $t$ - Statistic \\
\hline Constant & -1.87 & -4.52 \\
\hline Gender & 1.30 & 4.44 \\
\hline Trip-O & 1.36 & 3.94 \\
\hline Walking Time -3 & -0.88 & -2.23 \\
\hline Percent Time Difference & 8.39 & 6.74 \\
\hline Like-Lihood Ratio Index $\left(\rho^{2}\right)=0.43$ & & \\
\hline
\end{tabular}

Table value of $t$, @ 2.5\% level of significance, = 1.96

\subsection{Model Validation}

For the purpose of model validation, the holdout data set with 100 data points was used as follows: First, a separate model of modal shift using the data of the hold out sample was calibrated and Log-Likelihood $(L L)$ was es- timated. Next, the model initially calibrated using 400 data points applied to the hold out sample (with 100 data points) to predict modal shift and the value of $L L$ was calculated. Then, two values of $L L$ were compared for their closeness. The relevant details are given in Table 3.

Table 3. The results of model validation

\begin{tabular}{ccc}
\hline & \multicolumn{2}{c}{ Value of model statistics } \\
\cline { 2 - 3 } Description & $\begin{array}{c}\text { Model initially } \\
\text { calibrated with } 400 \\
\text { data points }\end{array}$ & $\begin{array}{c}\text { Model calibrated } \\
\text { using hold out } \\
\text { sample with 100 } \\
\text { data points }\end{array}$ \\
\hline Initial $L L$ & -276.57 & -70.01 \\
Final $L L$ & -158.47 & -39.76 \\
$\rho^{2}$ & 0.43 & 0.43 \\
\hline $\begin{array}{l}\text { Estimated } L L \text { for the model calibrated } \\
\text { using the hold out sample }\end{array}$ & -39.76 \\
\hline $\begin{array}{l}\text { Calculated } L L \text { by applying the model } \\
\text { initially calibrated based on } 400 \text { data } \\
\text { points in the hold out sample. }\end{array}$ & -34.54 \\
\hline
\end{tabular}

It can be seen that two Log-Likelihood values are close to each other, thus proving the validity of the model. The acceptable $\rho^{2}$ value ranges from 0.2 to 0.4 (Alvinsyah et al. 2005) and $\rho^{2}$ values of around 0.4 may give excellent fits (Ortúzar and Willumsen 2001). Hence, the result of validation may be considered to be satisfactory. 


\section{Sub Models Based on Trip Purpose}

Two different sub models for trips made for work and all other purposes (the number of trips made for education by using auto-rickshaw were found to be too small to build the model) were calibrated and validated following the same procedure explained in the previous section to study the shift behaviour of auto-rickshaw users. The model calibration and validation results are given in Table 4. It can be seen that the variables used in the models are statistically significant and two models are also valid. The probability of shift (for various travel time differences) from the auto-rickshaw to the bus estimated using the models presented in Table 5. It can be seen that, as expected, the higher is time difference (bus travel time is less than auto-rickshaw travel time) the higher is the probability of shift in all cases. It can also be noticed that for the given time difference, the probability of shift is maximum in the case of trips made for other purposes.

\section{Sub Models Considering Only Travel-Time Difference as the Influencing Variable}

For policy decisions on urban-transport-system management, it would be appropriate to consider the impact of changes on the operating characteristics of travel mode(s). Accordingly, in this case, it would be appropriate to estimate the probability of shift to the bus considering only travel-time as the influencing variable. Consequently, the models were calibrated and validated by considering travel-time difference as the only basis for modal shift following the same procedure explained in the previous section. Then, the calibrated models were used to predict the aggregate shift of auto-rickshaw users to the bus which is the only criterion considered being reduction in travel time. The calibration results are given in Table 6. The probability of shift for varying travel-time differences between the auto-rickshaw and the bus obtained using the calibrated models are presented in Table 7.

Table 4. The results of calibration and validation of the models based on trip purposes

\begin{tabular}{|c|c|c|c|c|}
\hline \multirow[b]{3}{*}{ Influencing variable } & \multicolumn{4}{|c|}{ Values of parameter and $t$-statistic } \\
\hline & \multicolumn{2}{|c|}{ Model based on trips for work purposes } & \multicolumn{2}{|c|}{ Model based on trips for other purposes } \\
\hline & $\begin{array}{l}\text { Parameter } \\
\text { estimate }\end{array}$ & $t$-statistic & $\begin{array}{l}\text { Parameter } \\
\text { estimate }\end{array}$ & $t$-statistic \\
\hline Constant & -0.42 & -0.87 & 0.11 & 0.33 \\
\hline Gender & 1.02 & 1.72 & 0.74 & 2.16 \\
\hline Walking Time 3 & -0.94 & -1.55 & -0.79 & -1.72 \\
\hline Time difference ${ }^{*}$ & 7.94 & 2.62 & 6.06 & 4.82 \\
\hline Likelihood Ratio Index $\left(\rho^{2}\right)$ & \multicolumn{2}{|c|}{0.28} & \multicolumn{2}{|c|}{0.43} \\
\hline \multicolumn{5}{|c|}{ Model validation } \\
\hline $\begin{array}{l}\rho^{2} \text { for the model calibrated using the hold } \\
\text { out sample }\end{array}$ & \multicolumn{2}{|c|}{0.30} & \multicolumn{2}{|c|}{0.44} \\
\hline $\begin{array}{l}\text { Estimated } L L \text { for the model calibrated } \\
\text { using the hold out sample }\end{array}$ & \multicolumn{2}{|c|}{-12.10} & \multicolumn{2}{|c|}{-29.60} \\
\hline $\begin{array}{l}\text { Calculated } L L \text { by applying the model } \\
\text { initially calibrated on the hold out sample }\end{array}$ & \multicolumn{2}{|c|}{-10.03} & \multicolumn{2}{|c|}{-25.59} \\
\hline
\end{tabular}

${ }^{\star}$ Percentage of bus and auto-rickshaw journey times

Table 5. The probability of the shift of auto-rickshaw users to the bus

\begin{tabular}{|c|c|c|c|}
\hline \multirow{2}{*}{$\begin{array}{c}\text { Percentage difference between bus } \\
\text { journey time and auto-rickshaw } \\
\text { journey time }\end{array}$} & \multirow{2}{*}{$\begin{array}{l}\text { Probability of } \\
\text { shift (considering trips } \\
\text { for all purposes) }\end{array}$} & \multicolumn{2}{|c|}{$\begin{array}{c}\text { Probability of } \\
\text { shift (based on trip-purpose) }\end{array}$} \\
\hline & & work & others \\
\hline 0 & 47.93 & 41.58 & 70.16 \\
\hline 10 & 68.05 & 61.14 & 81.09 \\
\hline 20 & 83.13 & 77.66 & 88.72 \\
\hline 30 & 91.94 & 88.48 & 93.51 \\
\hline 40 & 96.35 & 94.44 & 96.35 \\
\hline
\end{tabular}


Table 6. The results of the calibration and validation of models with travel-time difference as the only causal variable

\begin{tabular}{|c|c|c|c|c|c|c|}
\hline \multirow{3}{*}{ Influencing Variable } & \multirow{2}{*}{\multicolumn{2}{|c|}{$\begin{array}{l}\text { Model based on trips for } \\
\text { all purposes }\end{array}$}} & \multicolumn{4}{|c|}{ Values of parameter and $t$-statistic } \\
\hline & & & \multicolumn{2}{|c|}{$\begin{array}{l}\text { Model based on trips for } \\
\text { work purposes }\end{array}$} & \multicolumn{2}{|c|}{$\begin{array}{l}\text { Model based on trips for } \\
\text { other purposes }\end{array}$} \\
\hline & $\begin{array}{l}\text { Parameter } \\
\text { estimate }\end{array}$ & $t$-statistic & $\begin{array}{l}\text { Parameter } \\
\text { estimate }\end{array}$ & $t$-statistic & $\begin{array}{l}\text { Parameter } \\
\text { estimate }\end{array}$ & $t$-statistic \\
\hline Constant & -0.18 & -0.97 & -0.47 & -1.31 & 0.54 & 3.18 \\
\hline Time difference ${ }^{*}$ & 6.09 & 7.02 & 8.15 & 3.65 & 4.55 & 3.82 \\
\hline Likelihood Ratio Index $\left(\rho^{2}\right)$ & \multicolumn{2}{|c|}{0.27} & \multicolumn{2}{|c|}{0.24} & \multicolumn{2}{|c|}{0.36} \\
\hline \multicolumn{7}{|c|}{ Model Validation } \\
\hline $\begin{array}{c}\rho^{2} \text { for data set pertaining to the } \\
\text { holdout sample }\end{array}$ & \multicolumn{2}{|c|}{0.27} & \multicolumn{2}{|c|}{0.23} & \multicolumn{2}{|c|}{0.37} \\
\hline $\begin{array}{c}\text { Estimated } L L \text { for the model calibrated } \\
\text { using the hold out sample }\end{array}$ & \multicolumn{2}{|c|}{-51.37} & \multicolumn{2}{|c|}{-13.79} & \multicolumn{2}{|c|}{-33.43} \\
\hline $\begin{array}{c}\text { Calculated } L L \text { by applying the model, } \\
\text { initially calibrated, on the hold } \\
\text { out sample }\end{array}$ & \multicolumn{2}{|c|}{-44.28} & \multicolumn{2}{|c|}{-12.46} & \multicolumn{2}{|c|}{-40.38} \\
\hline
\end{tabular}

*Percentage of bus and auto-rickshaw journey times

Table 7. The probability of the shift of auto-rickshaw users to the bus estimated by taking travel-time difference as the only causal variable

\begin{tabular}{|c|c|c|c|}
\hline \multirow{2}{*}{$\begin{array}{l}\text { Percentage difference between bus } \\
\text { and } \\
\text { auto-rickshaw journey times }\end{array}$} & \multirow{2}{*}{$\begin{array}{l}\text { Probability of shift (considering trips } \\
\text { for all purposes) }\end{array}$} & \multicolumn{2}{|c|}{$\begin{array}{c}\text { Probability of } \\
\text { shift (based on trip purposes ) }\end{array}$} \\
\hline & & Work & Others \\
\hline 0 & 45.51 & 38.46 & 63.18 \\
\hline 10 & 60.56 & 58.54 & 73.01 \\
\hline 20 & 73.85 & 76.13 & 81.00 \\
\hline 30 & 83.85 & 87.81 & 87.05 \\
\hline 40 & 90.52 & 94.21 & 91.37 \\
\hline
\end{tabular}

\section{Modal Shift Probability Curve}

To illustrate the usefulness of the modal shift modelling exercise in urban road transport management, the developed aggregate modal shift model (involving all trips for different purposes) considering travel-time difference as the influencing variable was used to develop a modal shift probability curve (Fig. 3). As per the Indian Roads Congress (IRC) Technical Paper (IRC: 106-1990), the

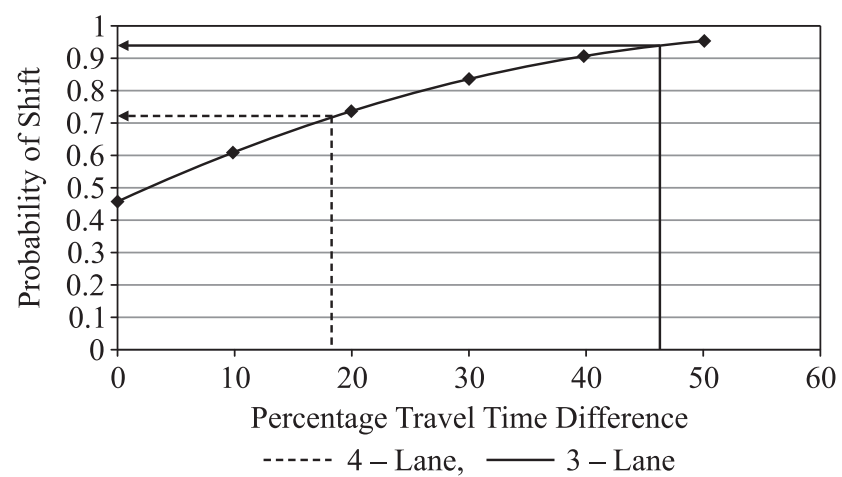

Fig. 3. The probability of the shift of auto-rickshaw users to bus recommended level of service for urban roads is ' $\mathrm{C}$ ' and the volume of traffic corresponding to this level of service can be taken as 0.7 times the capacity. Hence, the percentage at travel-time difference between the bus (on the exclusive lane) and the auto-rickshaw at volume corresponding to volume-to-capacity $(V / C)$ ratio value of 0.7 was determined using the simulation model. Percentage travel-time differences were 19 and 47 respectively for the roads with 14.5 and $11.0 \mathrm{~m}$ widths for the movement of traffic in one direction. The probability of shifts then can be obtained from the curve, as 0.92 and 0.72 for $11.0 \mathrm{~m}$ and $14.5 \mathrm{~m}$ wide road spaces respectively.

\section{Findings}

The following are the important findings of the study:

1. Through this study, a set of causal factors with reliable and predictable data base explaining variation in the shift behaviour of auto-rickshaw users to buses consequent on an increase in the level of bus service under Indian traffic conditions has been identified. The distinguished include gender, walking time to the bus stop, trip purpose and difference in travel time. 
2. The calibrated general logit model of modal shift (involving all trips and all variables) is found to be statistically significant with a satisfactory rho-square $\left(\rho^{2}\right)$ value. The model, when validated using the hold-out sample, was found to be valid based on the comparison of the predicted Log-Likelihood $(L L)$ value against the originally estimated $L L$ value.

3. Different models developed to facilitate understanding shift-behaviour changes with respect to trip purpose indicate that the probability of shift is maximum in the case of trips for other purposes.

4. The modal-shift model developed considering difference in travel-time as the causal variable is also found to be statistically valid and indicates the relatively high significance of the variable in explaining modal shift.

5. The modal-shift-probability curve drawn based on the modal shift model (involving all trips for different purposes) considering travel-time difference as the influencing variable can serve as a user-friendly simple tool to estimate modal shift probabilities. For example, it can be inferred from the curve that on city roads, at traffic flow corresponding to the level of service $C,(V / C=0.7)$, the probability of the shift of auto-rickshaw users to the bus after implementing an exclusive bus-lane scheme, is 0.92 for $11 \mathrm{~m}$ wide road and 0.72 for $14.5 \mathrm{~m}$ wide road.

\section{References}

Alvinsyah; Soehodho, S.; Nainggolan, P. J. 2005. Public transport user attitude based on choice model parameter characteristics (a case of Jakarta busway system), Journal of the Eastern Asia Society for Transportation Studies 6: 480-491.

Arasan, V. T.; Rengaraju, V. R.; Rao, K. V. K. 1996. Trip characteristics of travelers without vehicles, Journal of Transportation Engineering 122(1): 76-81.

Arasan, V. T.; Koshy, R. Z. 2005. Methodology for modeling highly heterogeneous traffic flow, Journal of Transportation Engineering 131(7): 544-551.

Basu, D.; Maitra, B. 2007. Valuing attributes of enhanced traffic information: an experience in Kolkata, Transport 22(3): 164-173.

Gebeyehu, M.; Takano, S. 2005. Modelling the relationship between seasonal constraints and modal choice characteristics of high school students in snowy region, Journal of the Eastern Asia Society for Transportation Studies 6: 1844-1857.

Gebeyehu, M.; Takano, S. 2007. Diagnostic evaluation of public transportation mode choice in Addis Ababa, Journal of Public Transportation 10(4): 27-50.

Ghareib, A. H. 1996. Evaluation of logit and probit models in mode-choice situation, Journal of Transportation Engineering 122(4): 282-290.

Hamed, M. M.; Easa, S. M. 1998. Integrated modeling of urban shopping activities, Journal of Urban Planning and Development 124(3): 115-131.

Indian Road Congress (IRC) Technical Paper IRC: 106-1990. Guidelines for Capacity of Urban Roads in Plain Areas. New Delhi, India.

Khaki, A. M.; Afandizadeh, Sh.; Moayedfar, R. 2009. Developing the composed probability model to predict household trip production (a case study of Isfahan city), Transport 24(1): 30-36.
Mackett, R. L. 2003. Why do people use their cars for short trips? Transportation 30(3): 329-349.

Nurdden, A.; Rahmat, R. A. O. K.; Ismail, A. 2007. Effect of transportation polices on modal shift from private car to public transport in Malaysia, Journal of Applied Sciences 7(7): 1013-1018.

Ortúzar, J. D.; Willumsen, L. G. 2001. Modelling Transport. 3rd Edition, Wiley. 514 p.

Rao, S. B. S. 1993. Sequential binary mode choice models for urban travel to work, Highway Research Bulletin 48: 91-107. Indian Road Congress (IRC), Highway research Board.

Tanczos, K.; Torok, A. 2007. Linear optimization model of urban areas' operating efficiency, Transport 22(3): 225-228.

Tischer. M. L.; Dobson, R. 1979. An empirical analysis of behavioral intentions of single-occupant auto drivers to shift to high occupancy vehicles, Transportation Research 13A: 143-158.

Ušpalytė-Vitkūnienė, R.; Burinskienė, M.; Grigonis, V. 2006. Calibration of Vilnius public transport model, Transport 21(3): 201-206.

Ziari, H.; Keymanesh, M. R.; Khabiri, M. M. 2007. Locating stations of public transportation vehicles for improving transit accessibility, Transport 22(2): 99-104. 